Research Article

\title{
Investigating the Material Removal Rate Parameters in ECM for Al 5086 Alloy-Reinforced Silicon Carbide/Flyash Hybrid Composites by Using Minitab-18
}

\author{
Bhiksha Gugulothu $\mathbb{D}^{1},{ }^{1}$ P. S. Satheesh Kumar, ${ }^{2}$ Bathula Srinivas, ${ }^{3}$ Alapati Ramakrishna, ${ }^{3}$ \\ and S. Vijayakumar ${ }^{3}$ \\ ${ }^{1}$ Department of Mechanical Engineering, Bule Hora University, Post box no-144, Oromia, Ethiopia \\ ${ }^{2}$ Department of Science and Humanities, AAA College of Engineering and Technology, Sivakasi, Virudhunagar District, \\ Tamil Nadu, India \\ ${ }^{3}$ Department of Mechanical Engineering, BVC Engineering College (Autonomous), Odalarevu 533210, Andhra Pradesh, India
}

Correspondence should be addressed to Bhiksha Gugulothu; bhikshamg@bhu.edu.et

Received 22 September 2021; Revised 5 October 2021; Accepted 21 October 2021; Published 3 November 2021

Academic Editor: V. Vijayan

Copyright (c) 2021 Bhiksha Gugulothu et al. This is an open access article distributed under the Creative Commons Attribution License, which permits unrestricted use, distribution, and reproduction in any medium, provided the original work is properly cited.

\begin{abstract}
This study explained about machining parameters of Al5086/Flyash/Sic hybrid metal matrix composites by the Taguchi technique. Al5086 reinforced in SiC (5-10 wt \%) and 8\% weight of flyash are retained as constants. The specimens are prepared with the help of the stir casting method. The material removal rate was examined by electrochemical machining under various parameters such as feed rate $(0.15-0.30 \mathrm{~mm} / \mathrm{min})$, voltage $(10-20 \mathrm{~V})$, and electrolyte concentration $(20-35 \mathrm{~g} /$ litre). Taguchi's L16 orthogonal array was selected for design of experiments (DOEs), and 16 experimental tests were conducted to examine the effect of the selected machining parameters employed to identify the best optimal levels and also to investigate the effect of electrochemical machining parameters on MRR determined by Minitab-18.
\end{abstract}

\section{Introduction}

MMC is used in various fields in everyday life [1]. Albased composites were extensively utilized in transportation fields, for example, automobiles, aerospace, making of engine machineries, and other industries [2]. The Al5083 composite is being used due to having a high specific strength and ease of production. It consists of many chemical elements such as $\mathrm{Si}, \mathrm{Mg}$, and $\mathrm{Mn}$. Even though many composites are present in the AA5086 alloy, $\mathrm{Mg}$ has maximum percentage benefit due to light weight. The 5086 alloy is used for various applications such as in missile components, uncooled and welded pressure vessels, marine components, and TV towers. SAESSI et al. discussed that wear mechanisms to mechanically milled Al5083 alloy and Al5083/5wt \% of B4C composite at room temperature (200 deg Celsius). Increment of temperature $200^{\circ} \mathrm{C}$ does not disturb the strength and hardness of surface layers in Al5083-5wt \%B4C in the wear test [3]. Stefanos established a composite of A1-4.5\% with $\mathrm{Cu}$ $1.5 \%-\mathrm{Mg}$ alloy with $\mathrm{SiC}$ particulates via the stir casting process. It is noticed that tensile and fatigue strength improved during matching with its cast and heat-treated state [4]. Basavarajappa et al. [5] investigated the outcome of sliding speed on the wear behavior test for a hybrid composite of Al-2219/15\% wt SiCp and Al2219/15\%SiCp$3 \%$ graphite produced by the liquid metallurgy method, and the result revealed that the degree of surface deformation increased while increasing slide speeds. $5059 \mathrm{Al}$ alloy reinforced with silicon carbide particles size (10-40 $\mathrm{lm}$ ) with 5 to $15 \mathrm{wt} \%$ and fixed $2 \%$ molybdenum disulphide was prepared by stir casing. MRR and SR have been investigated by varying machining parameters of voltage, feed rate, and concentration of electrolyte on the L27 
orthogonal array design of the experiments [6]. Al 6063 alloy was investigated by liquid and radiography tests, and an observation of the result shows that the die cast heattreated specimens had less faults compared to sand-casted materials [7]. SS304 pates were joined by the Tig weld process, the condition of the weld surface was analyzed by nondestructive testing which showed that hardness at the weld area is more than HAZ, and base metal and fusion zone region is improved with the assertion of heating [8]. Machining for EN45 material was conducted on ECM, and four input parameters were taken for the optimization process such as current, pulse-on time, pulse-off time, and voltage, and from result of ANOVA, it can be seen that peak current and pulse-off time are more significant factors for MRR [9]. Sometimes, interelectrode gap (IEG) is also considered as one of the input parameters on MRR [10]. Optimizing parameters of current, voltage, and electrolyte concentration in ECM of SKD 12 tool steel are analyzed with four levels [11]. Optimum process parameters for the desired performance measures are determined by Taguchi's $\mathrm{S} / \mathrm{N}$ ratio analysis and ANOVA table [12]. The combining of Sic on AA 5086 alloy with the help of GTA was carried out, and the surface appearances of the heated alloy were analysed by SEM and XRD. The composite materials' resistance of corrosion is less than that of the base metal [13]. The joining of Al5086 and Al 6061 alloys was performed by the FSW processes by change of different tool pins and hardness. Tensile strength was estimated on the weld area, and higher hardness values (83 HV) and higher tensile strength (169 MPa) were found in the stir zone [14]. Graphene (Gr) and silicon carbide ( $\mathrm{SiC}$ ) have been used as reinforcements which reinforced with aluminum (Al 5086) hybrid composite with the help of the FSW technique. Structure analysis and mechanical behavior of the prepared composites are carried out by the influence factors of cross speed, speed of the spindle tool, and geometry [15]. To develop lightweight composite materials with greater properties suitable for several industrial applications was the main focus of Praveen Kumar Swamy's research work. So, industrial wastes such as fly ash and S-glass-fibres have been used for reinforcement materials for high-strength alloy [16]. The surface roughness of the Al6061/SiC(12\%)/ $\operatorname{Gr}(5 \%)$ was increased with a surge of current, voltage, and pulse duration, and also, brass is the best electrode to achieve low surface roughness $(\mathrm{Ra})$. The material removal rate of the $\mathrm{Al}$ composites increased from 50 to $60 \%$ with the upsurge in current and pulse duration, while it drops by $20 \%$ with a rise in voltage [17]. Patil et al. revealed that optimum wear rate and microhardness may be induced in the AA7075-SiC/fly ash composites with the maximum $\mathrm{SiC}$ content. For inducing improvement in microhardness and wear behavior, the ratio of fly ash must be less than $20 \%$ and $13 \%$ in the mixture of SiC/fly ash combination, respectively [18].

In this study, optimization performance of ECM is a main consideration. Measurement of material removal rate for AA 5086-reinforced silicon carbide/Flyash needed to be examined. Moreover, the aim of this work is to find an optimal parameter influencing MRR during the process in the Taguchi approach, and a regression study has been executed for preferred performance features.

\section{Experimental Procedure}

2.1. Material Selection. Generally, aluminum alloy (Al5086) is best corrosion resistant material and is used as the main work metal in this investigation process. Two reinforcements were mixed with $\mathrm{Al}$ alloy at different weight propositions. The composite-Al5086/flyash/sic was prepared by the stir methodology. Tables 1 and 2 show the chemical elements of AA5086 and flyash, respectively.

2.2. Stir Casting Procedure. During the cast process, the base metal (5086) was placed and heated at about $750^{\circ} \mathrm{C}$. The next step was to preheat the selected reinforcements at 80 to $90^{\circ} \mathrm{C}$ for about 25 mins and then mix all metals together at a particular speed of the stirrer $(300 \mathrm{rpm})$ inside of the furnace; the stirrer was made of SS steel for avoiding oxidizing from molten metals during mix process for around 40 mins; after that, the molten materials were taken and poured in to shapeable cavity or die to create a sample for experimental works. Totally 16 specimens were formed by changing the percentage of SIC/flyash particles.

After preparation of samples, they were taken for the machining process in ECM (electrochemical machining) which is the removal of metal from the work surface as per our requirement depending on the reverse electroplating mechanism. Particles travelled from the work specimen (anode) towards the machine tool (cathode) during the process [6]. $\mathrm{NaCl}$ has been used as the electrolyte, and a cavity was produced on the material due to current or voltage passing on the setup (Figure 1); before and after the experimental work of ECM, weight of samples was measured by using a weighing apparatus. Density of composites was calculated from the formula

$$
\rho_{\text {composites }}=\rho V_{\text {A15086 }}+\rho V_{\text {Sic }+ \text { flyash }}
$$

where $\rho=$ density of $5086 \mathrm{Al}$ and $V_{\mathrm{Al} 5086}=$ volume of alloy.

Amongst the several methods, Taguchi for standard orthogonal array produces better parameters to be deliberated in various levels. In this paper, L16 was used as orthogonal array (OA) whose efficiency is proven in the experimental results. Parametric levels (F, L, and V) of machining are given in Table 3. Four levels of each parameter have been chosen for the design of experiments. Material removal rate is found by changing the machining factors of feed rate and voltage, as well as electrolyte volume. Based on MRR rate, $\mathrm{SN}$ ratio values were formulated by optimization software. With the aid of ANOVA of Minitab, the regression equation was found which expressed the relation between the input parameters and MRR.

$$
\operatorname{MRR}=0.00143+0.00887 F+0.000009 V+0.000013 E .
$$


TABle 1: Composition of AA5086.

\begin{tabular}{lcccccccc}
\hline Elements & $\mathrm{Si}$ & $\mathrm{Cu}$ & $\mathrm{Fe}$ & $\mathrm{Mg}$ & $\mathrm{Mn}$ & $\mathrm{Ti}$ & $\mathrm{Zn}$ & $\mathrm{Al}$ \\
\hline Percentage & 0.4 & 0.21 & 0.6 & 4.5 & 0.6 & 0.12 & 0.26 & Remaining \\
\hline
\end{tabular}

TABLe 2: Flyash composition (\% wt).

\begin{tabular}{lccccc}
\hline Elements & $\mathrm{SiO}_{2}$ & $\mathrm{Al}_{2} \mathrm{O}_{3}$ & $\mathrm{Fe}_{2} \mathrm{O}_{3}$ & $\mathrm{CaO}$ & $\mathrm{LOI}$ \\
\hline Percentage & $16-42$ & 23 & $6-10$ & $22-30$ & $1-3$ \\
\hline
\end{tabular}

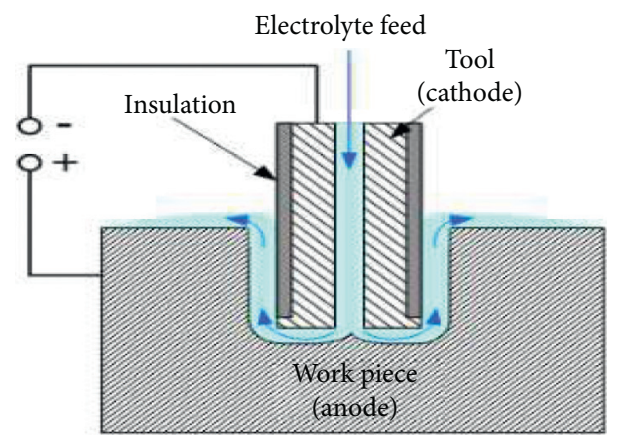

Figure 1: Electrochemical machining setup.

Table 3: Parameters of machining (four levels).

\begin{tabular}{lcccc}
\hline Parameters & Level 1 & Level 2 & Level 3 & Level 4 \\
\hline Feed rate (F) & 0.15 & 0.20 & 0.25 & 0.30 \\
Voltage (V) & 10 & 15 & 20 & 25 \\
Electrolyte concentration (E) & 20 & 25 & 30 & 35 \\
\hline
\end{tabular}

TABLE 4: Measured responses of machining.

\begin{tabular}{|c|c|c|c|c|c|c|c|}
\hline Exp. no. & $F(\mathrm{~mm} / \mathrm{min})$ & $\mathrm{V}$ (volt) & $E$ (g/litre) & $\operatorname{MRR}(\mathrm{mg} / \mathrm{min})$ & $\mathrm{SN}$ ratio & Fits & Residual \\
\hline 1 & 0.15 & 10 & 20 & 0.00275 & 51.2133 & 0.0031112 & -0.0003612 \\
\hline 2 & 0.20 & 15 & 25 & 0.00366 & 48.7304 & 0.0032237 & 0.0004363 \\
\hline 3 & 0.25 & 20 & 30 & 0.00284 & 50.9336 & 0.0033362 & -0.0004961 \\
\hline 4 & 0.30 & 25 & 35 & 0.00499 & 46.0380 & 0.0034487 & 0.0015413 \\
\hline 5 & 0.15 & 15 & 35 & 0.00315 & 50.0338 & 0.0036200 & -0.0004700 \\
\hline 6 & 0.20 & 20 & 20 & 0.00362 & 48.8258 & 0.0036014 & 0.0000186 \\
\hline 7 & 0.25 & 25 & 25 & 0.00242 & 52.3237 & 0.0038450 & -0.0014250 \\
\hline 8 & 0.30 & 10 & 30 & 0.00345 & 49.2436 & 0.0038264 & -0.0003764 \\
\hline 9 & 0.15 & 20 & 30 & 0.00549 & 45.2086 & 0.0041289 & 0.0013611 \\
\hline 10 & 0.20 & 25 & 35 & 0.00425 & 47.4322 & 0.0042414 & 0.0000086 \\
\hline 11 & 0.25 & 10 & 25 & 0.00434 & 47.2502 & 0.0040916 & 0.0002484 \\
\hline 12 & 0.30 & 15 & 20 & 0.00373 & 48.5658 & 0.0042041 & -0.0004741 \\
\hline 13 & 0.15 & 20 & 20 & 0.00415 & 47.6390 & 0.0046377 & -0.0004877 \\
\hline 14 & 0.20 & 25 & 35 & 0.00392 & 48.1343 & 0.0046190 & -0.0006990 \\
\hline 15 & 0.25 & 10 & 30 & 0.006617 & 43.5868 & 0.0046004 & 0.0020166 \\
\hline 16 & 0.30 & 15 & 25 & 0.00374 & 48.5426 & 0.0045817 & -0.0008417 \\
\hline
\end{tabular}

\section{Results and Discussion}

Three important parameters were selected as the leading portion of the present research. The outcomes of the experimental test were analyzed with help of ANOVA at 95\% confidence level, also estimating the effect of chosen variables (F, V, and E). SN ratio, fits for MRR results, and plots are shown in Table 4 and Figure 2. It was observed that the best optimal parameters combinations are F3-V4-E2 (SN value- $=52.3237$ ), i.e., F-
$0.25 \mathrm{~mm} / \mathrm{min}, \mathrm{V}-25 \mathrm{~V}$, and $\mathrm{E}-25 \mathrm{~g} / \mathrm{litre}$, and the least parameters groupings, which means the lowest optimal values, are F- $0.15 \mathrm{~mm} / \mathrm{min}, \mathrm{V}-20 \mathrm{~V}$, and E- $30 \mathrm{~g} /$ litre. Similarly, fitted values of MRR combinations are displayed in Figure 3, and it was found that the greatest and least optimization parameter arrangements are F2-V3-E4 $(0.20 \mathrm{~mm} / \mathrm{min}, 20 \mathrm{~V}, 35 \mathrm{~g} /$ litre $)$ and F1-V1-E1 (0.15 mm/min, $10 \mathrm{~V}, 20 \mathrm{~g} /$ litre), respectively (Table 4).

Table 5 reveals that $\mathrm{SN}$ response of matching parameters, feed rate level 2 (50.11) has more influence on the level of 


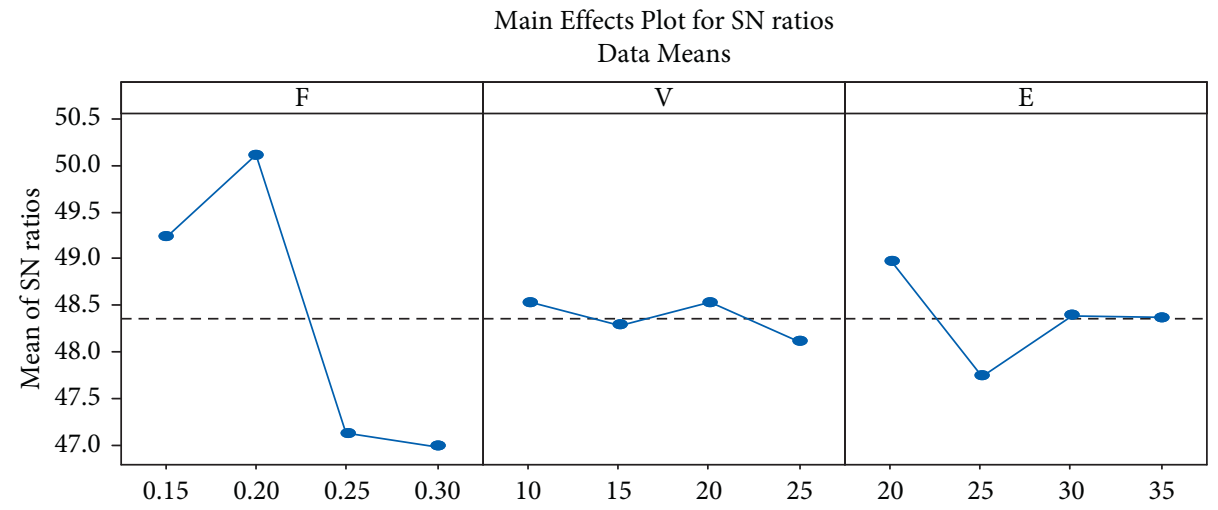

FIGURE 2: SN ratio plot of MRR parameters.

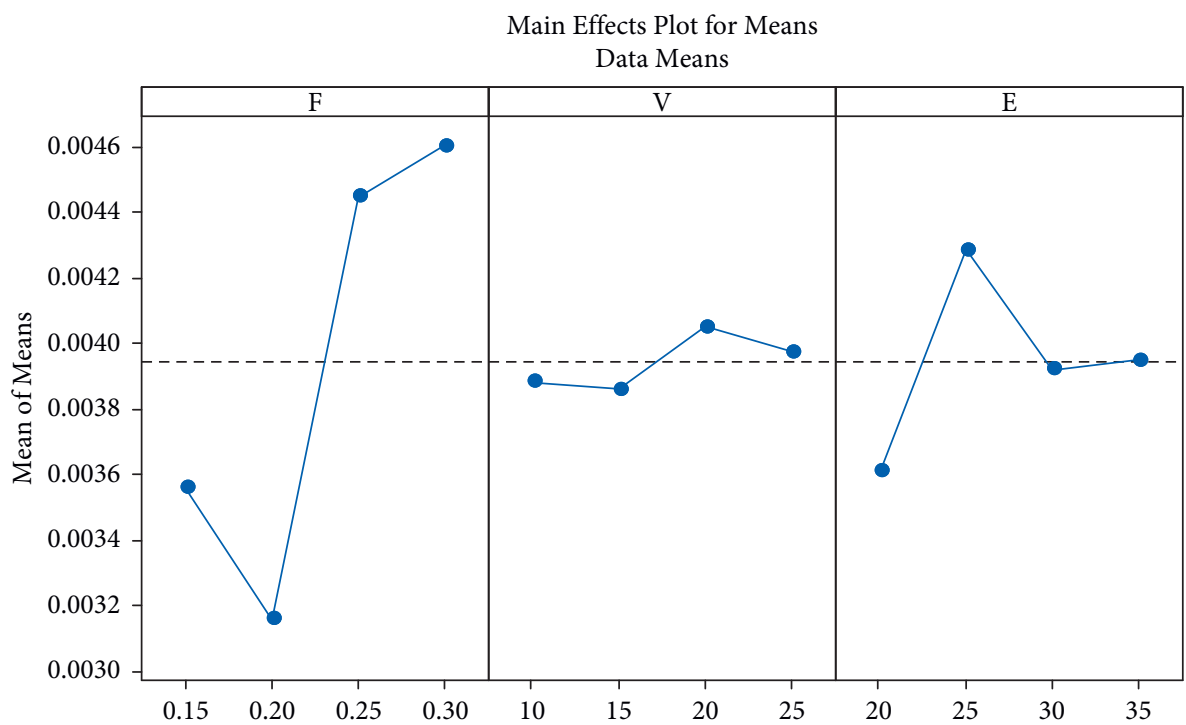

Figure 3: Fits plot of machining (MRR).

TABLE 5: SN response of machining.

\begin{tabular}{lccc}
\hline Level & $F$ & $V$ & $E$ \\
\hline 1 & 49.23 & 48.52 & 48.96 \\
2 & 50.11 & 48.28 & 47.73 \\
3 & 47.11 & 48.52 & 48.38 \\
4 & 46.98 & 48.10 & 48.36 \\
Delta & 3.13 & 0.43 & 1.23 \\
Rank & 1 & 3 & 2 \\
\hline
\end{tabular}

TABLE 6: Fits response.

\begin{tabular}{lccr}
\hline Level & $F$ & $V$ & $E$ \\
\hline 1 & 0.003560 & 0.003885 & 0.003613 \\
2 & 0.003160 & 0.003863 & 0.004289 \\
3 & 0.004452 & 0.004054 & 0.003925 \\
4 & 0.004607 & 0.003978 & 0.003953 \\
Delta & 0.001447 & 0.000192 & 0.000677 \\
Rank & 1 & 3 & 2 \\
\hline
\end{tabular}




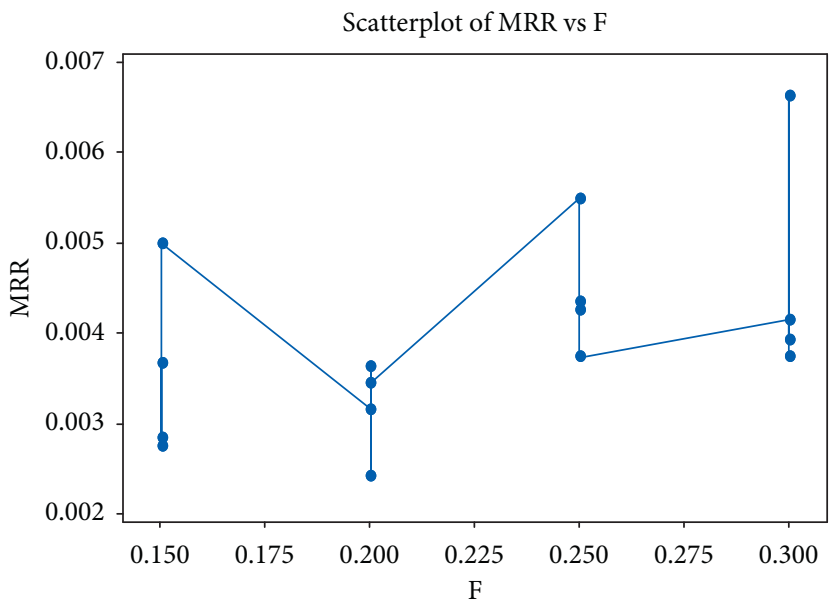

(a)

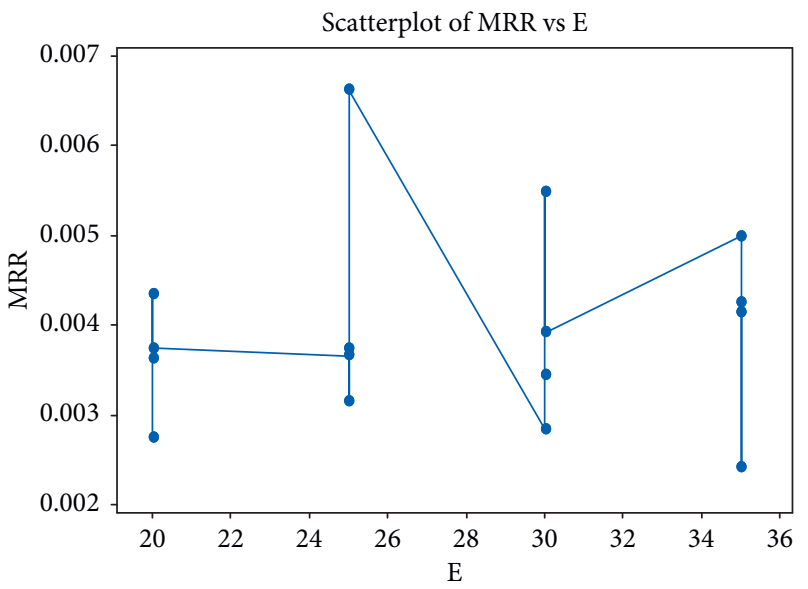

(c)

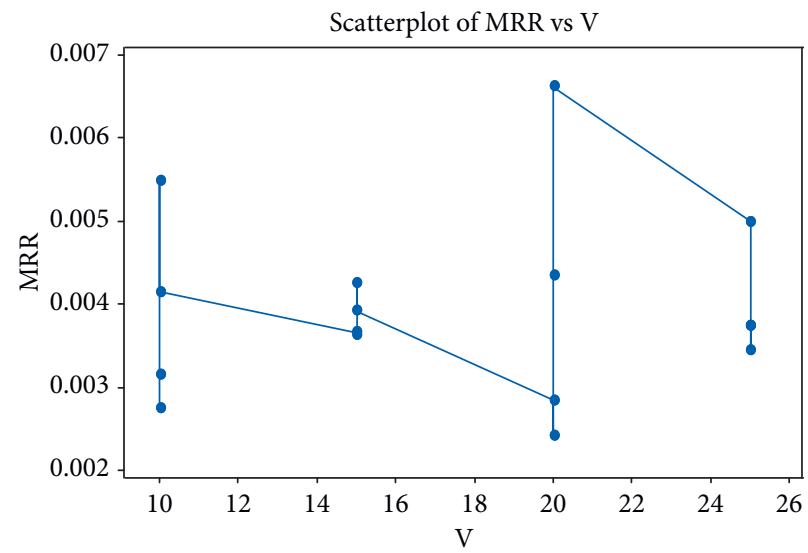

(b)

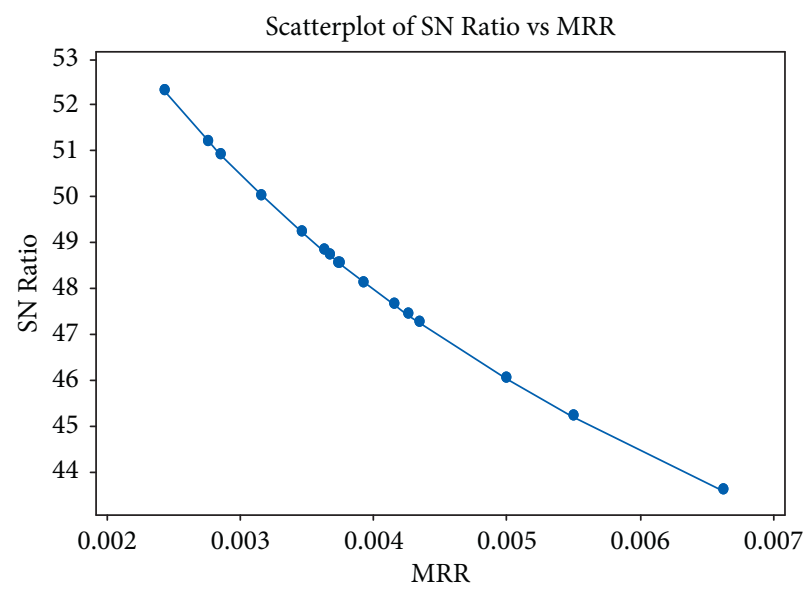

(d)

FIgURE 4: (a): MRR vs. feed rate. (b) MRR vs. voltage. (c) MRR vs. electrolyte concentration. (d) MRR vs. SN ratio.

TABLE 7: ANOVA result for machining (MRR).

\begin{tabular}{lccccccc}
\hline Source & DF & Seq-SS & Adj-SS & Adj-MS & $F$ value & $P$ value & Contribution (\%) \\
\hline$F$ & 3 & 0.000008 & 0.000006 & 0.000002 & 1.15 & 0.404 & 47 \\
$V$ & 3 & 0.000003 & 0.000000 & 0.000000 & 0.02 & 0.996 & 0.906 \\
$E$ & 3 & 0.000004 & 0.000001 & 0.000000 & 0.18 & & 17.6 \\
Residual error & 6 & 0.000002 & 0.000010 & 0.000002 & & & 11.8 \\
Total & 15 & 0.000017 & & & & \\
\hline
\end{tabular}

material removal rate followed by electrolyte concentration level 1 (48.96) and voltage level 3 (48.52). Similarly, fits response are shown in Table 6 in which F4 has most influence factor followed by V4 and E2.

The material removal rate was increased due to increase of feed rate and voltage (Figures $4(\mathrm{a})$ and $4(\mathrm{~b})$ ) and slightly decreased while increasing electrolyte concentration (Figure 4(c)). The graph between MRR and SN ratio is displayed in Figure 4(d) where both are reverse propositional to each other.

ANOVA results are formulated from statistical software Minitab-18 version. The contribution of each parameters selected for optimization analysis is exposed (Table 7); from the statement, it was observed that feed rate $(47 \%)$ is the leading parameter influencing the material removal rate of aluminum composite material (Al-5083/flyash/Sic), and electrolyte concentration $(23.5 \%)$ is the 2 nd influencing factor followed by voltage value (17.6\%).

\section{Conclusions}

Aluminium hybrid metal matrix samples (16) have been prepared through the stir casting technique by adding two reinforcement materials (Sic and flyash) with Al5086 alloy. The material removal rate of these samples was determined by electrochemical machining (ECM) under different 
parameters of feed rate, voltage, and electrolyte concentration. The design of experiments (L16 array) was conducted on Minitab statistical software. It was observed that MRR was increased due to increase of feed rate and voltage and slightly decreased by electrolyte concentration. Finally, feed rate $(47 \%)$ is the primary parameter influencing the material removal rate of Al5086/Sic/Flyash composites followed by electrolyte concentration (23.5\%) and voltage value $(17.6 \%)$. In the future, we are planning to increase the parameters and levels to more than three to find perfect optimal values of MRR.

\section{Data Availability}

The data used to support the findings of this study are included in the article. Further data or information are available from the corresponding author upon request.

\section{Conflicts of Interest}

This work was performed as a part of the employment at Bule Hora University, Ethiopia.

\section{Acknowledgments}

The authors appreciate the technical assistance to complete this experimental work from the Department of Mechanical Engineering, Bule Hora University, Ethiopia. The author thanks BVC Engineering College (Autonomous), Andhra Pradesh, for the support in draft writing.

\section{References}

[1] S. Ravindran, N. Mani, S. Balaji, M. Abhijith, and K. Surendaran, "Mechanical behaviour of aluminium hybrid metal matrix composites - a review," Materials Today: Proceedings, vol. 16, pp. 1020-1033, 2019.

[2] M. Ravi Kumar, H. N. Reddappa, R. Suresh, and M. Gangadharappa, "Effect of heat treatment on tensile strength of Al7075/Al2O3/SiCp hybrid composite by stir casting technique," Materials Today: Proceedings, vol. 5, no. 10 , pp. $22460-22465,2018$.

[3] M. Saessi, A. Alizadeh, and A. Abdollahi, "Wear behavior and dry sliding tribological properties of ultra-fine grained Al5083 alloy and boron carbide-reinforced Al5083-based composite at room and elevated temperatures," Transactions of Nonferrous Metals Society of China, vol. 31, no. 1, pp. 74-91, 2021.

[4] S. Skolianos, "Mechanical behavior of cast SiCp-reinforced $\mathrm{Al}-4.5 \% \mathrm{Cu}-1.5 \% \mathrm{Mg}$ alloy," Materials Science and Engineering A, vol. 210, no. 1-2, pp. 76-82, 1996.

[5] S. Basavarajappa, G. Chandramohan, A. Mahadevan, M. Thangavelu, R. Subramanian, and P. Gopalakrishnan, "Influence of sliding speed on the dry sliding wear behaviour and the subsurface deformation on hybrid metal matrix composite," Wear, vol. 262, no. 7-8, pp. 1007-1012, 2007.

[6] S. A. A. Daniel, S. V. Ananth, A. Parthiban, and S. Sivaganesan, "Optimization of machining parameters in electro chemical machining of Al5059/SiC/MoS2 composites using taguchi method," Materials Today: Proceedings, vol. 21, no. xxxx, pp. 738-743, 2020.

[7] P. Paramasivam and S. Vijayakumar, "Mechanical characterization of aluminium alloy 6063 using destructive and non- destructive testing," Materials Today: Proceedings, vol. xxxx, 2021.

[8] A. Prakash Pasupulla, H. Abebe Agisho, S. Seetharaman, and S. Vijayakumar, "Characterization and analysis of TIG welded stainless steel 304 alloy plates using radiography and destructive testing techniques," Materials Today: Proceedings, vol. xxxx, pp. 6-9, 2021.

[9] S. Raj and K. Kumar, "Optimization and prediction of material removing rate in die sinking electro discharge machining of EN45 steel tool," Materials Today: Proceedings, vol. 2, no. 4-5, pp. 2346-2352, 2015.

[10] N. Nagaraju, R. Surya Prakash, G. Venkata Ajay Kumar, and N. G. Ujwala, "Optimization of electrical discharge machining process parameters for 17-7 $\mathrm{PH}$ stainless steel by using taguchi technique," Materials Today: Proceedings, vol. 24, pp. 1541-1551, 2020.

[11] J. Jeykrishnan, B. V. Ramnath, C. Elanchezhian, and S. Akilesh, "Parametric analysis on electro-chemical machining of SKD-12 tool steel," Materials Today: Proceedings, vol. 4, no. 2, pp. 3760-3766, 2017.

[12] N. Manikandan, S. Kumanan, and C. Sathiyanarayanan, "Multiple performance optimization of electrochemical drilling of inconel 625 using taguchi based grey relational analysis," Engineering Science and Technology, an International Journal, vol. 20, no. 2, pp. 662-671, 2017.

[13] A. Shanmugasundaram, S. Arul, and R. Sellamuthu, "Study on the effect of GTA surface melting and SiC reinforcement on the hardness, wear and corrosion properties of AA 5086," Materials Today: Proceedings, vol. 5, no. 2, pp. 6597-6606, 2018.

[14] M. Ilangovan, S. Rajendra Boopathy, and V. Balasubramanian, "Effect of tool pin profile on microstructure and tensile properties of friction stir welded dissimilar AA 6061-AA 5086 aluminium alloy joints," Defence Technology, vol. 11, no. 2, pp. 174-184, 2015.

[15] G. S. Raheja, S. Singh, and C. Prakash, "Processing and characterization of Al5086-Gr-SiC hybrid surface composite using friction stir technique," Materials Today: Proceedings, vol. 28, no. xxxx, pp. 1350-1354, 2020.

[16] P. K. Swamy, S. Mylaraiah, M. P. Gowdru Chandrashekarappa et al., "Corrosion behaviour of high-strength $\mathrm{Al} 7005$ alloy and its composites reinforced with industrial waste-based fly ash and glass fibre: comparison of stir cast and extrusion conditions," Materials, vol. 14, no. 14, pp. 3929-4017, 2021.

[17] M. Singh, S. Maharana, A. Yadav et al., "An experimental investigation on the material removal rate and surface roughness of a hybrid aluminum metal matrix composite (Al6061/sic/gr)," Metals, vol. 11, no. 9, pp. 1449-1512, 2021.

[18] N. A. Patil, S. R. Pedapati, O. B. Mamat, and A. M. Hidayat Syah Lubis, "Effect of SiC/fly ash reinforcement on surface properties of aluminum 7075 hybrid composites," Coatings, vol. 10, no. 6, pp. 541-6, 2020. 